Beate Strittmatter

\title{
ZAHN VERURSACHT SCHMERZ IN DER RECHTEN WADE
}

$\mathrm{E}$ in 34-jähriger Handwerkermeister wird von seinem Orthopäden zu mir geschickt wegen eines therapieresistenten Schmerzes in der rechten Wade. Der Patient beschreibt ein Kältegefühl und einen ziehenden Schmerz beim Joggen. Allgemeinmedizinisch ließ sich bisher ein Hartspann derWadenmuskulatur und eine zeitweise Minderdurchblutung in diesem Bereich feststellen. Alle anderen bildgebenden oder laborchemischen Verfahren waren ohne Besonderheiten.

Bei der Störherduntersuchung finde ich einen starken Herd im sogenannten verdeckten System: Zahn 15 (rechter Oberkiefer) (Abb. 1).

Das Problem: Der Zahn ist im Röntgenbild nicht auffällig (wie mir auch der Zahnarzt versichert) und er reagiert im Kältetest vital. Die zum Zahn gehörige BahrLaserfrequenz 7 zeigt nicht nur Resonanz zum Zahn selbst, sondern auch RAC-Resonanz über dem Areal der rechten Wade am Ohr, was bedeutet, dass dieser geklagte Wadenschmerz mit einem Zahnstörherd zu tun hat bzw. von diesem unterhalten wird.

Ich versuche zunächst alles über eine stärkende $\mathrm{Aku}-$ punkturbehandlung: Symptompunkt rechte Wade als Zangentechnik (Schmerzpunkt vorn, Punkte der Muskulatur auf der Ohrrückseite), Einbeziehung des zugehörigen Meridians, Narbenstörherde antientzündliche Punkte am Ohr usw. Es ändert auch nach mehreren Sitzungen nichts an der Problematik.

Letztendlich wage ich es, den Zahnarzt zu bitten, den Zahn aufzubohren.

Ergebnis: Der unklare weiße Schatten stellt sich heraus als breiter Keramikstift, den ein vorheriger Zahnarzt zur Befestigung einer Füllung oder in dem Versuch einer Wurzelbehandlung in den Zahn getrieben hat. Allerdings als via falsa, d.h. einfach in die Zahnsubstanz und nicht in den Zahnkanal. Die Pulpa selbst ist vital, aber hochentzündet.

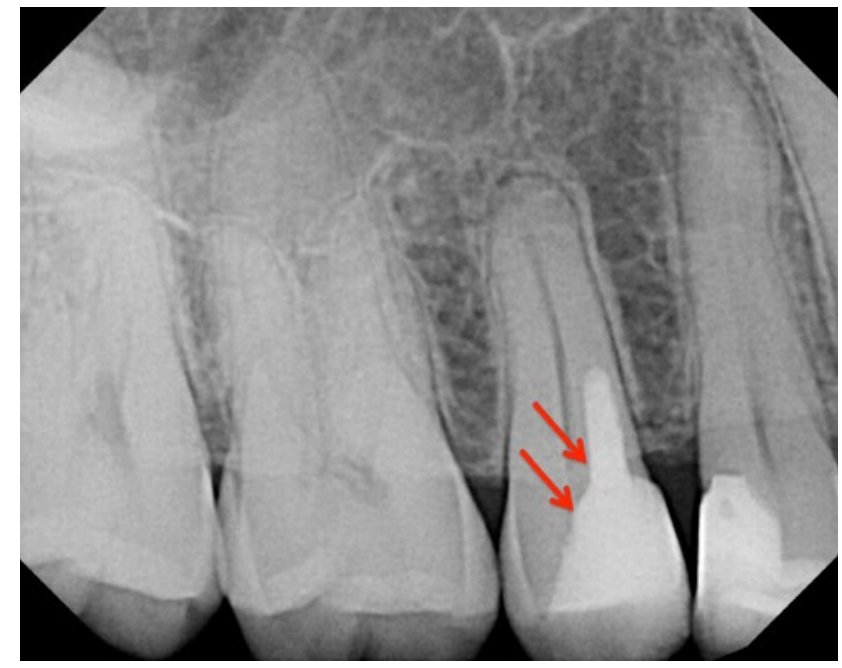

Der Patient berichtet: Mit dem Setzen der Leitungsanästhesie verschwand der Wadenschmerz noch auf dem Zahnarztstuhl! Der Zahnarzt führt eine sorgfältige Wurzelbehandlung durch, der Zahn hatte sogar zwei Wurzelkanäle.

Im Störherdtest hört daraufhin der Zahn auf, zu stören. Anfangs gab es jede Woche einmal eine kleine Schmerzerinnerung beim Joggen - kein Vergleich zum Schmerz vor der Behandlung. Ich lasere daraufhin den Zahn über der Zahnwurzel und der Wurzelspitze von außen, Fr. 7, direkter Kontakt mit dem Zahnfleisch, 70mW Dauerstrich-Infrarot. Daraufhin hört der Schmerz völlig auf und ist bis heute nicht mehr aufgetreten.

Der Patient ist darüber informiert, dass es sinnvoll ist, den Zahn halbjährlich auf Herdaktivität testen zu lassen.

Fazit: Zähne sind immer wieder für erstaunliche Symptome verantwortlich. Und: Manch einen üblen Zahnstörherd kann man auf einer normalen Zahn-Übersichtsaufnahme (OPG) nicht entdecken.

Dr. B. Strittmatter

FA für Allgemeinmedizin, Naturheilverfahren, Akupunktur, Sportmedizin

Ausbildungsleiterin Ohrakupunktur

Saarbrücken

Strittmatter@t-online.de 